\title{
A DINÂMICA DE PARTICIPAÇ̃̃O SOCIAL NOS CONSELHOS MUNICIPAIS DE CULTURA DA BAIXADA FLUMINENSE
}

\author{
THE DYNAMICS OF SOCIAL PARTICIPATION IN THE BAIXADA FLUMINENSE MUNICIPAL \\ COUNCILS OF CULTURE
}

\author{
Recebido em 19.05.2017. Aprovado em 28.08.2017 \\ Avaliado pelo sistema double blind review \\ DOI: http://dx.doi.org/10.12712/rpca.v11i4.986
}

\section{Marina Teixeira Gonçalves}

Universidade Federal do Rio Grande do Sul (UFRGS), Porto Alegre/RS, BRASIL

marinatgoncalves@gmail.com

\section{Janaína Machado Simões}

Universidade Federal Rural do Rio de Janeiro (UFRRJ), Seropédica/RJ, BRASIL

janainamsimoes@gmail.com

\section{Resumo}

Dentre as várias áreas nas quais os conselhos representam importante papel no desenvolvimento de políticas públicas, está a área da cultura. A reflexão sobre novas formas de gestão pública na área da cultura passa a ter ligação direta com mecanismos e espaços para a promoção da participação social, sendo os conselhos municipais de cultura componentes centrais nesse processo. Diante disso, o presente trabalho tem por objetivo entender a dinâmica de participação social nos conselhos municipais de cultura da Baixada Fluminense. Partindo de uma metodologia qualitativa e de uma discussão teórica sobre participação, concluise que o processo de participação social nos conselhos municipais de cultura da Baixada Fluminense acontece de forma limitada devido à natureza das políticas públicas e das organizações que determinam a estrutura destes. Além disso, as características da gestão e as relações de poder entre os atores envolvidos também influenciam a dinâmica participativa nos conselhos.

Palavras-chave: Participação Social. Conselhos Municipais de Cultura. Baixada Fluminense.

\begin{abstract}
Among the many areas in which the councils play an important role in the development of public policies is the area of culture. The reflection on new forms of public management in the area of culture is now linked directly with mechanisms and spaces for the promotion of social participation, and the municipal councils of culture are central components in this process. Therefore, the present work aims to understand the dynamics of social participation in the municipal councils of culture of the Baixada Fluminense. Based on a qualitative methodology and a theoretical discussion about participation, it is concluded that the process of social participation in the municipal councils of culture of Baixada Fluminense happens in a limited way due to the nature of the public policies and organizations that determine their structure. In addition, the characteristics of management and the power relations between the actors involved also influence the participatory dynamics in the councils.
\end{abstract}

Keywords: Social Participation. Municipal Councils of Culture. Baixada Fluminense. 


\section{Introdução}

As discussões sobre conselhos de políticas públicas afirmam que eles têm por finalidade garantir o diálogo entre a sociedade civil e o poder público, além de exercer controle social e fiscalizar a execução das políticas públicas e dos serviços. Por isso, Teixeira (2005) indica que os conselhos foram criados com o objetivo de partilhar o poder e descentralizar as decisões. Dessa forma, os conselhos têm como proposta ser um espaço que busca a resolução de conflitos entre os interesses da sociedade e do poder público. Logo, a participação social passa a ser elemento fundamental na discussão sobre a efetividade dos conselhos.

Dentre as várias áreas nas quais os conselhos representam importante papel no desenvolvimento de políticas públicas, está a área da cultura. Nos últimos dez anos, a área de políticas culturais vem passando por transformações, como a formulação do Plano Nacional de Cultura e do Sistema Nacional de Cultura, as quais fizeram com que as formas de elaborar políticas nesta área fossem repensadas. A reflexão sobre novas formas de gestão pública na área da cultura passa a ter ligação direta com mecanismos e espaços para a promoção da participação social, sendo os conselhos municipais da cultura componentes centrais nesse processo.

A Baixada Fluminense a partir das diretrizes de políticas culturais federais e estaduais conseguiu, nos últimos anos, uma maior centralidade nos debates sobre a incorporação da cultura na agenda pública. Além de ampliar a participação e a articulação da sociedade civil no campo da cultura do estado do Rio de Janeiro, os municípios da Baixada Fluminense promoveram uma série de iniciativas em torno do desenvolvimento de espaços de diálogo e participação, como por exemplo, fóruns, conferências e, especialmente, os conselhos municipais de políticas culturais.

Embora tenham ocorrido avanços na construção de instâncias participativas na área da cultura nos municípios da Baixada Fluminense, é possível identificar diversos desafios no planejamento e na implantação dessas iniciativas. Verifica-se que ainda há a necessidade de considerar as especificidades regionais em seus processos de elaboração de políticas culturais e ampliar a participação da sociedade civil para uma maior efetividade dos conselhos nas decisões dos municípios. Diante disso, o presente trabalho tem por objetivo entender a dinâmica de participação social nos conselhos municipais de cultura da Baixada Fluminense.

\section{A dinâmica de participação social no contexto brasileiro}

De acordo com Demo (2009, p.18) "participação é conquista", porque não é algo que existe por si mesmo, já que deve ser conquistado. Para o autor, a liberdade e a participação só são legitimas quando conquistadas. Mesmo assim, conforme afirma Canedo (2009, p. 88), "aparticipaşão é um processo de aprendizado que contribuipara o empoderamento da população no sentido do fortalecimento de sujeitos autônomos, com consciência crítica."

Tenório (1990) indica que a participação é uma prática social, é fazer políticas, é repensar o seu saber em confrontos com outros saberes. Assim, é possível entender os participantes como grupos sociais que estão envolvidos com os problemas locais e pretendem articular ações que beneficiem as comunidades, podendo ser estes ativos no campo político, social, cultural ou econômico (TENÓRIO et al 2008). Dessa forma, o objetivo da participação visa impedir que as decisões fiquem concentradas no poder público e na minoria pertencente às classes dominantes, e deve garantir a igualdade de direitos e oportunidades por todos aqueles que poderão ser atingidos pelas ações (TENÓRIO ET AL, 2008).

De acordo com Bordenave (1983), a etimologia da palavra participação vem do termo "parte". Participação é então "fazer parte, tomar parte ou ter parte" (BORDENAVE, 1983, p. 22). Porém, para o autor esses termos não dão o mesmo significado para participação, porque fazer parte e tomar parte são diferentes, em que a primeira representa uma participação passiva, e a segunda a participação ativa.

Para Bordenave (1983) há diversas maneiras de participar, tais como: participação de fato, participação espontânea, participação imposta, participação voluntária, participação provocada (dirigida ou manipulada) e participação concedida. Assim, para o autor, o nível de participação estaria diretamente relacionado com o grau de controle dos membros sobre as decisões e a importância das decisões que tomam, partindo de um nível informativo, de consulta, de consulta obrigatória, de elaboração/recomendação, de cogestão, de delegação até a auto-gestão.

Bordenave (1983) também estabelece que existem dois tipos de processos de participação: a microparticipação e a macroparticipação. Segundo ele, a microparticipação acontece em grupos primários ainda, dentro da própria família, amizade e vizinhança e 
também em grupos secundários, como as associações, empresas e sindicatos. Já a macroparticipação também pode ser chamada de participação social, que consiste na intervenção em movimentos sociais que prevêem mudanças na sociedade (BORDENAVE, 1983).

No que diz respeito à macroparticipação, Bordenave (1983) discute alguns fatores que são condicionamentos desfavoráveis à participação. Para o autor, o primeiro condicionante é a questão da desigualdade, que não se limita à esfera social, mas alcança também a esfera política, que não há oportunidade para todos na participação política no país.

Além disso, Maranhão e Teixeira (2006) explicitam quatro desafios para a participação cidadã: articulação entre a participação e o modelo de desenvolvimento, falta de eficácia e efetividade dos canais de participação, fortalecimento das práticas de participação e necessidades de articulação entre todos os espaços participativos.

Nesse sentido, Ammann (1978) defende que a participação não deve ser um evento isolado e acidental, mas um processo dialético e consolidado no cotidiano dos cidadãos. Sendo assim, a intensidade da participação de uma sociedade acaba sendo influenciada pelas condições e oportunidades para participar, podendo esses meios ser conquistados pelas camadas populares ou não (AMMANN, 1978).

Segundo Tenório et al (2008), o Estado tem o papel de ser apenas um facilitador das ações dos grupos sociais que favoreçam o bem de todos. Então, a participação pode ser vista como o caminho para a democratização das políticas públicas no Brasil, mas também pode ser uma forma de legitimar e reforçar as práticas autoritárias do Estado (MARANHÃO, TEIXEIRA, 2006).

Todavia, não se pode desprezar a importância da participação institucionalizada na sociedade atual. A participação institucionalizada é quando a participação acontece por meio de algum canal de interação e diálogo formal, guiado por regras para decidir sobre políticas públicas (ABERS, SERAFIM e TATAGIBA, 2014). Estes canais podem ter sido estabelecidos por meio de movimentos sociais ou protesto, ou ainda por órgãos estatais, o que também vai definir a forma como essa participação será conduzida (ABERS, SERAFIM e TATAGIBA, 2014). É predominante no Brasil a participação institucionalizada principalmente em forma de conselhos de políticas públicas, orçamento participativo e conferências públicas (ABERS,
SERAFIM e TATAGIBA, 2014).

Costa e Cunha (2010) contestam várias questões em torno da participação social no Brasil, apresentando sete teses equivocadas que tem baseado as ações políticas no país. A primeira tese é que o Estado no Brasil institui a cidadania, sendo a presença deste muito forte e predominante na criação de instituições que possibilitem a participação (COSTA e CUNHA, 2010). Complementando a primeira, a segunda tese é de que a única cidadania possível é a estadania, na qual o Estado é tido como o agente educador e civilizador, crendo que o Estado é um ator neutro, porém num país caracterizado por desigualdades extremas, acabase por privilegiar grupos da elite e reforçar e perpetuar a dominação estatal (COSTA;CUNHA, 2010).

Por outro lado, a terceira tese discute que é a estadania que torna a cidadania possível, pois o Estado que define como dever ser a participação, quem participa, quais os caminhos para a participação (COSTA;CUNHA, 2010). Assim, embora instâncias participativas sejam criadas, estas são dependentes da atuação do Estado para existir e funcionar (COSTA;CUNHA, 2010). Já a quarta tese afirma que a participação contribui para fortalecer os mecanismos de formulação e implementação de políticas e a efetividade já existentes (COSTA;CUNHA, 2010). Assim, nem mesmo a presença de fóruns e conselhos garante o aumento da governabilidade, já que com a regulação da participação pelo Estado, as decisões concentram-se em grupos que detêm maior recursos de conhecimento e riquezas (COSTA;CUNHA, 2010).

A quinta tese equivocada é que a participação garante a sustentabilidade aos programas sociais, perpetuando ações que apenas amenizariam os problemas. (COSTA,CUNHA, 2010). Já na sexta tese, os autores questionam o fato da participação estimular uma gestão democrática, pois pode servir de desagregação social, já que os grupos não pensam no bem comum, e são capazes de prejudicar outros grupos sociais para alcançar os benefícios almejados. Por último, os autores Costa e Cunha (2010) indicam que os espaços de participação não são suficientes para promover a participação, já que os obstáculos políticos e culturais também são um empecilho nesse processo.

Além disso, Costa e Cunha (2010) destacam quatros fatores que impedem a participação:

\footnotetext{
“(1) cooptação de lideranças populares por grupos ou facções partidárias; (2) ausência de democracia interna nas organizações
} 
da sociedade civil e no aparelho de estado, reforçando o elitismo e a centralização de poder decisório; (3) escassez de informações aos interessados sobre o andamento das políticas; e (4) inadequada capacitação dos representantes populares para lidar com a complexidade técnica de algumas decisões." (COSTA; CUNHA, 2010, p. 548)

Portanto, ainda que a introdução dos mecanismos de participação social represente uma ampliação dos direitos sociais, não é suficiente por si só para garantir a plena participação (FLEIG, OLIVEIRA e BRITO, 2006). Para isso, os autores acreditam serem necessárias ações conjuntas a esses canais de participação para propagação de informações e conscientização da importância da participação social. Contudo, apesar das limitações das organizações participativas, é preciso reconhecer que essas organizações são importantes para fortalecimento das práticas participativas e por isso o Estado e a sociedade devem se empenhar para que elas avancem ainda mais (FLEIG, OLIVEIRA e BRITO, 2006).

Nesse sentido, entende-se que os conselhos devem proporcionar um espaço de debate e representar um lugar para ouvir as demandas culturais e fortalecer a participação social (FARIA, 2009). Assim, conforme Faria (2009, p. 102) afirma, um conselho: "deveria potencializar atores culturais, promover a aproximação entre sociedade e governo, ouvir rumores de criatividade pública e contribuir para a criação da esfera pública da cultura".

\section{Metodologia}

A presente pesquisa, com o fim de atingir o objetivo proposto, utilizou a perspectiva qualitativa, seguindo as etapas propostas por Minayo (2012): (1) fase exploratória; (2) trabalho de campo; (3) análise e tratamento do material empírico e documental. A pesquisa foidelimitada na regiãoda BaixadaFluminense, Segundo o IBGE (2009), a Baixada Fluminense faz parte da Região Metropolitana do Estado do Rio de Janeiro que é composta por 13 municípios: Belford Roxo, Duque de Caxias, Guapimirim, Itaguaí, Japeri, Magé, Mesquita, Nilópolis, Nova Iguaçu, Paracambi, Queimados, São João de Meriti e Seropédica. Dessa forma, foram estudados os conselhos municipais de políticas culturais desses municípios.

Sendo assim, para o trabalho de campo realizouse pesquisa documental, observação e entrevistas semiestruturadas. Os critérios utilizados para a seleção dos sujeitos entrevistados foram: (a) ser atuante no contexto cultural da Baixada Fluminense, como artista, gestor ou conselheiro; (b) participar ou ter participado de um conselho municipal de cultura na Baixada Fluminense. A partir dessa delimitação, foram realizadas 24 entrevistas. $\mathrm{Na}$ análise, os entrevistados representantes do poder público estão sinalizados como "PP" e os conselheiros da sociedade civil como "SC" juntamente com o nome do município que fazem parte.

Por fim, a análise de dados foi feita por meio de análise de conteúdo, que visa categorizar as entrevistas e dados de acordo com frases, palavras e conteúdos (ROESCH, 1996). Para tanto foram definidas as seguintes categorias de análise tendo por base a teoria: formas de participação, tomada de decisão, controle, papel da sociedade civil, conflitos e relações de poder. Por fim, a categoria cultura e desenvolvimento foram criadas posteriormente, em função do conteúdo evidenciado nas entrevistas.

\section{0 processo de participação social nos conselhos municipais de cultura na Baixada Fluminense}

O conselho de políticas culturais, de acordo com as definições utilizadas no Brasil, é:

\begin{abstract}
"uma instância colegiada permanente, de caráter consultivo e deliberativo, integrante da estrutura político-administrativa do Poder Executivo, constituído por membros do Poder Público e da Sociedade Civil. Criado por lei, tem como principais atribuições: propor e aprovar, a partir das decisões tomadas nas conferências, as diretrizes gerais do Plano de Cultura e acompanhar sua execução; apreciar e aprovar as diretrizes gerais do Sistema de Financiamento à Cultura e acompanhar o funcionamento dos seus instrumentos, em especial o Fundo de Cultura; e fiscalizar a aplicação dos recursos recebidos decorrentes das transferências federativas." (MINC, 2011, p. 27).
\end{abstract}

Os conselhos municipais de políticas culturais estão inseridos nos sistemas nacional, estaduais e municipais de cultura. O município para aderir ao Sistema Municipal de Cultura (SMC), ilustrado na figura 1, deve assinar um acordo de cooperação federativa do SNC e 
implementar uma lei municipal que legitime as ações, e também estabeleça ligações entre os elementos do SMC (MINC, 2011).

Figura 1. Sistema Municipal de Cultura

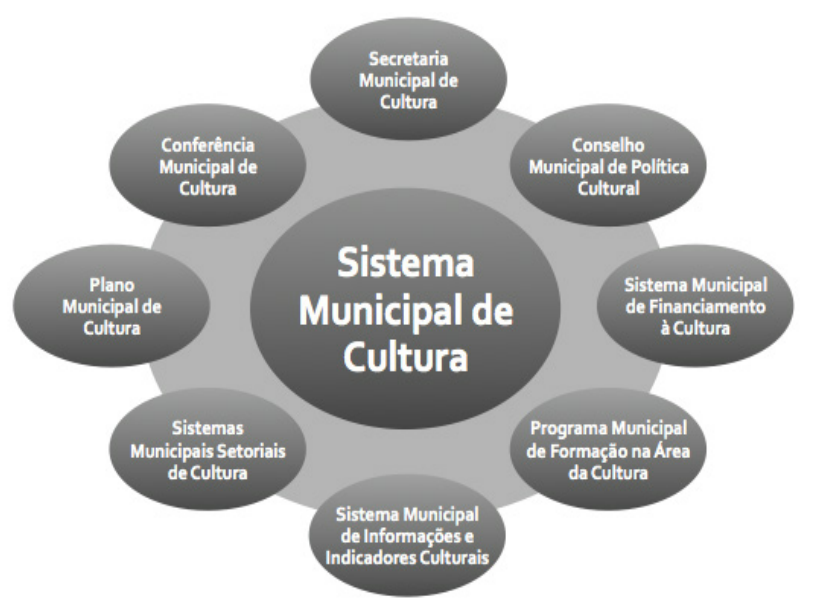

Fonte: MINC, 2011.

Além disso, o conselho deve acompanhar a execução das diretrizes do PNC, bem como fiscalizar a utilização dos recursos financeiros da área (MINC, 2011). Quanto à composição do conselho, o SNC prevê que seja composto por $50 \%$ dos membros vindos da sociedade civil eleitos de forma democrática (MINC, 2011). Dessa forma, os conselhos costumam tomar suas decisões através de reuniões colegiadas periódicas. Portanto, com o objetivo de caracterizar a dinâmica de participação dos conselhos de políticas culturais, o quadro 1 , a seguir, descreve as principais características encontradas nas reuniões desses conselhos.

Quadro 1. Caracterização da reunião dos conselhos

\section{Características \\ da reunião}

Convocação

\section{Características Gerais dos} Conselhos Municipais de Cultura

Antes do início do ano, é elaborado um calendário anual com as datas das reuniões mensais. Além disso, as convocações são feitas via e-mail, também por meio das redes sociais, dos sites dos conselhos e por telefone, quando disponibilizado pela secretaria. Porém, alguns conselheiros ao longo das reuniões reclamaram de não haver mais divulgação sobre a data da reunião.
Cenário

A maioria das reuniões ocorrerem na própria secretaria de cultura ou em alguma organização pública cultural.

Espaço A estrutura é bem simples, apenas algumas cadeiras e mesa. Sendo que na maioria das vezes, todos sentados em volta da mesa em círculo, ou distribuídos informalmente.

Condução da Esse foi um ponto que variou reunião muito de conselho para conselho. Nos regimentos, de forma geral, é estabelecido que a condução da reunião deve ser feita pelo presidente, e na ausência deste, pelo secretário geral. Mas, em alguns casos, a condução da reunião não segue formalidades e é definida pelos conselheiros.

Controle Hora O horário é uma questão importante na reunião, os conselheiros sempre se preocupam bastante com o horário que vai terminar, e ficam receosos da reunião se estender demais. Entretanto, em alguns lugares, o controle não é tão rígido.

Encerramento Geralmente, não há um encerramento formal, as pessoas vão deixando a reunião, e em virtude da falta de quórum a reunião acaba.

Fonte: elaborado pelas autoras a partir das observações nas reuniões.

O quadro 2, por sua vez, trata de descrever as principais características do processo de participação social nas reuniões colegiadas periódicas dos conselhos municipais de cultura da Baixada Fluminense. 
Quadro 2 . Descrição da dinâmica da reunião dos conselhos

\section{Dinâmica da Características Gerais dos Reunião Conselhos Municipais de Cultura}

$\mathrm{D}$ e c i s õ e s $\mathrm{Na}$ maioria das reuniões observadas Tomadas não houve tomada de decisão, algumas porque não havia quórum, outras porque a reunião foi informal. Algumas decisões ficam centradas na figura do presidente, sendo o voto apenas legitimador. Observam-se demandas por mais representantes da sociedade civil. Também há processos informais de tomada de decisão, em que a votação não ocorreu.

A $\quad \mathrm{t} \quad \mathrm{o} \quad \mathrm{r} \quad \mathrm{e} \quad \mathrm{s}$ Os atores desses conselhos são envolvidos representantes da sociedade civil e representantes do poder público. Quase todos os conselhos são paritários, com exceção do conselho de Nova Iguaçu que é tripartidário, dividido entre poder público, sociedade civil e artistas. Os conselheiros da sociedade civil são pessoas engajadas com a cultura do município, representantes de várias manifestações culturais. Já os conselheiros do poder público são pessoas que trabalham nas secretarias municipais, que não possuem histórico de trabalho na cultura, com algumas exceções de alguns militantes de cultura que foram convidados a trabalhar no órgão municipal de cultura.

G $\quad r \quad u \quad p \quad o \quad s$ Não foi possível ter uma visão existentes clara sobre os grupos presentes em cada conselho. Porém, em alguns momentos ficou claro o embate entre poder público e sociedade civil.

Representação Não há uma paridade real, já que em alguns conselhos a maioria frequentadora representa o poder público. A ausência dos conselheiros da sociedade civil é recorrente, ocorrendo pela dificuldade de mobilização ou mesmo por resistência. Já quando há uma oposição do governo ao conselho, a ausência dos conselheiros do poder público é verificada.
Processo de Com algumas exceções, de Comunicação processos formais em geral, o processo de comunicação acontece informalmente, no qual ocorre a exposição de ideias por parte dos conselheiros e o debate se estabelece.

Fonte: elaborado pelas autoras a partir das observações nas reuniões.

A partir da observação nas reuniões dos conselhos e do próprio desenho institucional das políticas culturais propostas pelo MINC percebe-se que a dimensão organizacional das instâncias participativas ainda precisa ser discutida. Embora a expectativa seja de que esses espaços favoreçam a participação da sociedade, o formato organizacional dos conselhos demonstra- um predomínio burocrático que impacta fortemente nos mecanismos de participação e no desenvolvimento de espaços mais deliberativos e autônomos.

O primeiro aspecto a ser observado sobre o processo de participação diz respeito às suas formas. Os dados abaixo mostram que a participação social nos conselhos é prevista pelas leis, e por isso, podem se assemelhar ao que Bordenave (1983) chama de participação concedida, uma participação legitimada. "Bom, vou falar da experiência aqui.
Tinha-se uma lei de criação né, na lei
de criação, estava elencado lá, quais as
instituições que participam né. Então, tem
lá, são seis instituições governamentais,
e seis não governamentais. Essa lei de
criação, ela foi feita baseada na lei orgânica
do município, onde prevê como será as
questões da cultura, e lá prevê também
a criação do conselho, ai, a gente faz um
ofício, enquanto secretaria de cultura pras
instituições, convocando pra uma reunião,
foi assim, que a gente fez, convocando
para uma reunião, para falar sobre o
conselho de cultura."

(PP Japeri)

"Pra ser eleita? Bom, no poder público
é a indicação do próprio secretário e na
sociedade civil é a participação no fórum
e estar dentro daqueles requisitos que a lei
pede, as atribuições que a lei pede." (PP
Nilópolis 1)

"E, as instituições presentes, se candidatam, ai a gente já tem a lei que fala, que dispõe 
sobre o sistema, sistema municipal não, sobre a organização da cultura na cidade né, essa lei prevê como será, como é, como deve ser o conselho, fala como é, como as instituições devem representar, como podem ser as instituições que representam.”(PP Queimados 1)

Para Bordenave (1983), a participação concedida é fazer com que a participação se restrinja aos grupos primários. E a partir dos relatos acima, nota-se que a participação nos conselhos em geral é concedida, e limitada pela legislação. Segundo Abers, Serafim e Tatagiba (2014) os espaços participativos podem ser estabelecidos pelos movimentos sociais ou pelos órgãos públicos, porém isso vai determinar a forma como a participação será conduzida. Dessa forma, como os conselhos municipais de políticas culturais são reflexos de uma política implementada pelo Estado, consequentemente as regras estabelecidas acabam limitando o estabelecimento de mecanismos mais deliberativos de participação nos conselhos.

"Divulgando mesmo! Divulgando e pedindo pelo amor de Deus às vezes, né? Poxa, olha, é o Conselho. A gente precisa que o Conselho aconteça e a gente precisa da ajuda de vocês. Precisa que vocês participem! E mais assim mesmo. Boca a boca!" (PP Japeri 2)

\footnotetext{
"Não sei nem como te responder isso.. Porque na realidade eu vim por indicação... Eu participei por indicação...É...A maioria das instituições que participam do conselho, elas acompanham o trabalho do conselho, ou tem algum outro tipo de relação ou com a secretaria. Então geralmente quando chega a época da conferência, essas instituições elas já estão e já tem mais ou menos uma ideia do período e elas começam a se mobilizar... Inscrever delegados, as pessoas que vão participar.'(SC Caxias)
}

A partir dos relatos acima é possível perceber pouco estímulo para a participação, já que há poucas atividades de divulgação dos conselhos, não há atividades de conscientização da importância da participação. Isso impede muitas vezes que o conselho tenha participantes suficientes para o funcionamento.

"Sendo ativos na área cultural, fazendo parte de uma instituição cultural, sendo artista, sendo membro de alguma associação cultural e nos procurando, procurando vir as conferencias né, porque a gente abre as inscrições pras conferencias. $\mathrm{E}$ vir ate a secretaria de cultura pra ter mais informações, o que é um conselho como funciona, como a gente trabalha."

(PP Guapimirim)

"É isso que eu te falei: elas tem que
ser indicadas por uma instituição!Por
exemplo, uma instituição ligada a cultura.
(...) Mas, tem que ter CNPJ! Tem que
ter CNPJ (seu) registrado. É isso que
eu falei, que eu queria acabar com isso
lá. Por exemplo, você...(pausa) poderia
representar o Conselho sem precisar de
nada por trás."(Poder Público Caxias)

$\mathrm{Na}$ maioria dos conselhos municipais de cultura da Baixada Fluminense a participação social acontece por meio de organizações da sociedade civil que tenham CNPJ e trabalho cultural na comunidade. Sendo assim, limita-se a participação, não possibilitando a participação de todos que queiram. Por conta das exigências legais, há alto grau de formalidade na participação. Para fazer parte dos conselhos municipais de cultura, o conselheiro tem que passar por todas as etapas necessárias.

O segundo ponto importante a ser analisado sobre a participação é que o processo de tomada de decisão está diretamente relacionado com o nível de participação social Por isso, quanto mais estratégicas as decisões tomadas pelo conselho, maior o nível de participação social por meio dele. Entretanto, há alguns impedimentos para que as decisões sejam tomadas dentro do conselho com a participação social, muitas vezes, o conselho é apenas informado da decisão tomada.

As principais atividades dos conselhos municipais de cultura são as reuniões colegiadas, sendo assim, as decisões costumam acontecer por meio do voto. Porém, Bordenave (1983) diz que para participação social de fato, só acontece quando a população além do direito ao voto é detentora dos meios de produção cultural e material.

"Através de votação mesmo. Na maioria a gente tem um tema pra ser discutido, e a gente faz uma avaliação da proposta qualquer membro do conselho pode trazer uma proposta, ou alguma necessidade, no momento a gente vai colocar em pauta e vai votar.’(PP Guapimirim) 
"A tomada de decisão é democrática, participativa, não é, como todos os conselhos. As reuniões pra acontecerem tem que ter quórum, o quórum é metade mais um, e a partir desse quórum também dali vão ser feitas as votações no mesmo sentido, não é, ganha a proposta ou a decisão que tiver maioria de voto, é assim que é feito. É registrado em ata, (..) aquela decisão ta valendo pro resto ne, pro resto do mandato.”(PP São João de Meriti)

"Através de voto, tudo é uma pauta, é uma inscrição, é aberta a inscrição, então as pessoas se inscrevem e a gente vai analisando lá e decide tudo por votação. Como eu falei antes, nada no Conselho é decidido no eu, tudo é decidido através do voto e vence a maioria."(PP Mesquita)

Diante dos trechos acima, pode-se concluir que a tomada de decisão acontece formalmente, para que a decisão seja acatada, ela deve seguir as formalidades exigidas, de ter quórum, de contar os votos e de registro em ata.

"Tem que estar o Conselho todo, e aí é a maioria. Questão de maioria , e o voto de minerva é do presidente."(PP Japeri 2)

"O Presidente, por lei, sempre é o Secretário de Cultura...Que é uma coisa que eu acho que é errada...porque em vários momentos em que se tinha um assunto relevante para ser votado, e se dependia do voto de minerva, por lei o voto de minerva é do presidente do conselho, nós...a sociedade civil sempre perde...porque o representante do governo, o secretário, sempre vai votar a favor do governo."(SC Caxias)

De acordo com Paula (2005), apesar de a vertente gerencial considerar a participação social, as decisões mais importantes são decididas no núcleo estratégico da organização. Essa prática tem sido comum também nos conselhos municipais de cultura, em que a decisão final é centralizada no presidente. Para Bordenave (1983) esse nível de participação é a consulta facultativa, em que a decisão fica a cargo dos dirigentes e os subordinados apenas opinam sobre a decisão. Isso ocorre porque segundo Maranhão e Teixeira (2006) houve ampliação dos processos participativos

no Brasil, mas não uma reforma administrativa.

\begin{abstract}
"é... uma mais democrática... algumas são democráticas..umas decisões mais.. é... que tem uma influência um pouco... como é que pode ser.. como é que pode dizer... é algumas coisas são a gente mesmo né! que acha que deve fazer que não votação, maioria vence, pá. Mas tem algumas coisas que também é decidida por ele pelo poder público . Ai já vêm já meio amarradinho." (SC Japeri)
\end{abstract}

\begin{abstract}
"Mas, 99\% das vezes há uma concordância total. O que eu nem acho tão negativo, o que eu acho negativo é que só há esse informe por parte da secretaria para o conselho, não há um questionamento do conselho, e muito menos, o que eu acho um pouco mais complicado, não também por parte do conselho, uma preposição, uma construção de demanda, que sai do conselho para a secretaria, as demandas são sempre da secretaria para o conselho." (PP Queimados 1)
\end{abstract}

Conforme relatado nos trechos acima, em muitos casos, o conselho é apenas informado da decisão tomada previamente pelo poder público. Para Bordenave (1983), o nível mais básico de participação é quando os participantes são apenas informados das decisões depois que estas são tomadas, mas mesmo assim, já pode ser considerado participação. Porém, Carvalho (2009) afirma que esta prática enfraquece a participação e os espaços participativos são usados para legitimar ações do Estado.

\begin{abstract}
"Apesar de que a gente já teve momentos aqui no conselho de que ficava prevalecendo a vontade do Presidente. Ele tomou a decisão de falar que era aquilo e acabou...ponto final." (SC Caxias)
\end{abstract}

Então, nota-se que algumas decisões são influenciadas por grupos, em que a maioria segue as decisões tomadas. Por isso, Costa e Cunha (2010) salientam que a presença dos conselhos não é garantia do aumento da governabilidade da sociedade civil. Os conselhos, conforme Barbalho (2009) alega, têm se tornado uma estrutura corporativa visando alcançar o interesse de um grupo e não da maioria da sociedade.

Outro ponto importante é que nos relatos de entrevistas, observa-se que as decisões levadas para votação, na maioria das vezes, são de baixa importância 
para a cultura do município. Estas são apenas decisões referentes à própria organização do conselho, mas nada que influencie a política cultural do município.

Já o terceiro aspecto importante sobre a participação é que a participação social está diretamente relacionada com o nível de controle que determinado grupo tem sobre as decisões tomadas (BORDENAVE,1983). Por isso, para entender a dinâmica da participação social nos conselhos, é preciso saber como acontece o controle das atividades.

Nos trechos abaixo é possível ver que os conselheiros têm pouco controle sobre as atividades.

\begin{abstract}
"É, a cada reunião, a gente senta, a gente avalia o que aconteceu, o que não aconteceu, o que a gente tem que replanejar, o que ta dando certo, o que a gente vai continuar. E, através de, toda reunião é feito uma ata, toda reunião tem o registro da ata, todos assinam" (PP Japeri)
\end{abstract}

\begin{abstract}
"Através das reuniões. Essas reuniões que eu te falei que a gente tem, reunião quinzenal, reunião mensal. A gente tem as nossas atas as nossas pastas, tem a direção do conselho, e é assim que funciona." (PP Guapimirim)
\end{abstract}

Como a principal atividade exercida pelos conselhos são as reuniões mensais e elas são registradas em ata, o controle acontece via procedimentos formais. Porém, alguns conselhos há relatos de que várias atas não foram feitas, e que isso tem dificultado o controle.

"Bom, a gente tem as atas né, e a única atividade que o conselho tá tendo ultimamente são as reuniões." (PP Nilópolis 1)

"Controle de que? Nesse momento controle de que... Nós temos as atas e nessas atas é falado tudo que acontece na reunião. Tudo que nós fechamos e acordamos está atreves de uma ata. E aí lá vai dizer se nós fizemos, ou não fizemos, ou quanto fizemos. É uma forma de controle." (SC SJM)

"É uma cobrança quase coletiva do que ta acontecendo ou o que não está acontecendo, é uma cobrança nas reuniões mesmo. E também assim, não são atividades, não acontecem atividades com freqüência, não tem uma coisa assim, estamos sempre em atividade, sempre temos demandas a serem divididas, e entendeu?" (PP Queimados 1)

Conforme descrito anteriormente nos trechos de entrevista, os conselhos não realizam muitas ações de controle. A única atividade contínua são as reuniões mensais.

\begin{abstract}
"Deveria ser feito em ata... o controle, então se ele elege uma mesa diretora e essa mesa diretora tem um secretário exatamente pra que esse secretário tome nota de tudo que é discutido na reunião, de preferência que ele grave mas não é obrigatório gravar, se faz lá a ata exatamente pra ficar registrado, porque senão o conselho começa a ficar como uma pessoa esquizofrênica, ela delibera uma coisa, propõe uma coisa, delibera aquela deliberação, delibera aquela proposição, toma uma decisão, vamos fazer isso, aí não faz.”(PP NI)
\end{abstract}

\begin{abstract}
"Quem controla o conselho é a sociedade civil, se a sociedade civil achar que na conferência os conselhos não fez um bom papel ela pode trocar seus conselheiros. O governo não, ele que troca depois que se encerra os mandatos ou modifica, não existe um controle assim.” (PP Caxias)
\end{abstract}

“É um pouco de autogestão né...Porque o conselho ele tem ata, tem que produzir uma ata daquela reunião. E essa ata tem que tá disponível pra quem é de direito. A forma de você socializar a informação é dar publicidade.Então a ata é o principal caminho pra você dar acesso a informação.”(SC Mesquita)

"O controle passa pela secretaria, comigo como presidente...A gente que controla todas as atividades.”(PP Queimados 2)

Então, é possível perceber que nos conselhos municipais de cultura da Baixada Fluminense não há um processo de controle claramente definido, com etapas e critérios, eles acontecem, em sua maioria, informalmente ao longo das reuniões.

O quarto elemento a ser observado sobre a participação é sobre o papel da sociedade civil. Alguns autores acreditam que a participação só é efetiva se a sociedade civil conquista os espaços de participação, enquanto outros entendem que a participação - 
mesmo que de forma limitada - também pode acontecer em espaços estabelecidos pelo estado. Da mesma forma, os conselheiros também possuem opiniões divergentes quanto ao papel da sociedade civil. Alguns representantes do poder público acham que a sociedade civil precisa se mobilizar mais para tornar esses canais efetivos. Já os conselheiros da sociedade civil acreditam que o poder público coloca empecilhos para a participação social.

"Eu acho que a população consegue fazer esse movimento, se a população cobra, ai fica mais fácil.” (PP Japeri)

"Eu acho é isso que... desistir não é o papel. Mas eu acho que a sociedade precisa se empoderar mais. De que forma? Acho que com parceria. Parceria também de entidade que realmente queira ver uma cultura ampla (...) a cultura pode mudar sim muito dessas pessoas. $\mathrm{O}$ que falta, as vezes, é conhecimento, acesso, entendimento. E que a instituição pode ajudar." (PP Mesquita)

Alguns conselheiros reclamam sobre a falta de empoderamento na sociedade civil.

Logo, é possível observar que quando a participação que acontece nos conselhos é limitada, a sociedade civil é vista como uma aliada para cumprir os planos dos governos. Castro e Mattos (2009) sugerem que a institucionalização das práticas sociais pode levar ao congelamento dos objetivos iniciais. Sendo assim, a formalização do conselho pode influenciar no nível da participação social.

"Algumas pessoas que estavam, que se
ofereceram né, porque o conselho é isso,
a pessoa se oferece, sabe-se que não há
um recurso, (...) não há uma gratificação
pra sociedade civil, é quem é sociedade
civil, participaria, teoricamente participaria
disso, por interesse e engajamento
pessoal, de tentar transformar algo. " (PP
Queimados1)

Outra dificuldade enfrentada para a participação social é a falta de estímulo. Segundo Ammann (1978), não é o bastante oferecer apenas os meios para participação, mas também incentivar, informar e conscientizar sobre a questão.

"há uma necessidade muito de... de... um... 'só que há uma falta... das pessoas daqui saber a importância deles no conselho, saber a importância delas no... na associação de moradores, onde eles vão só reclamar né!... que era o que só aconteceu isso lá... mas ela não sabe... seria bem bacana se eles estivessem lá... porque há.. um diálogo, uma cobrança na verdade seria bem mais validade se tivesse se... se o poder publico visse que na verdade não só meia dizias de pessoas que estão ali falando"(SC Nilópolis 1)

No relato acima, nota-se que há uma responsabilização da sociedade civil no funcionamento nos conselhos municipais de cultura da Baixada Fluminense.

Isso ocorre porque segundo Maranhão e Teixeira (2006) houve ampliação dos processos participativos no Brasil, mas não uma reforma administrativa.

O quinto elemento a ser entendido sobre o processo de participação diz respeito à existência de conflitos e relações de poder. Os conflitos são elementos inerentes à dinâmica do processo de participação social, estão sempre presentes nos espaços de participação social. Sendo assim, entender as principais questões que envolvem os conflitos nos conselhos é fundamental para caracterizar a dinâmica da participação social. Nas entrevistas quase todos os conselheiros citaram os conflitos de ideias como sendo corriqueiros no diaa-dia dos conselhos municipais de cultura.
"é... eles são resolvidos através de votação mesmo. votação” (SC JAPERI)
"Bom vai pra votação nua e crua, ai a gente tem esse cenário de votação como eu falei agora a pouco e o que a levou a atual situação que o conflito maior o esvaziamento do conselho não foi resolvido, ainda continua apresentando um esvaziamento" (SC Nilópolis 1)

Os conflitos existentes, portanto, costumam ser resolvidos por voto. Os conselhos por serem órgãos colegiados têm como prática que as decisões sejam resolvidas em conjunto. Entretanto, muitas vezes, quando a decisão escolhida não é favorável para um grupo, os conflitos são levados para o pessoal.

"É, aí é dos conflitos dos mais variados, a
alguém que questiona algum tipo de ação
ou que acha que não foi comunicado a
altura, ou alguém acha que determinada
área tá sendo mais privilegiada do que
outras áreas e a gente como poder publico 
vê que não tem jeito, porque não tem jeito, o tempo inteiro você tem que eleger prioridades, e abranger tudo e o tempo inteiro é impossível. Então, você vai ter que definir prioridades e ,é, vai sempre ter alguém que vai tá um pouco mais, é, contemplado do que outros. É, e a gente precisa tá lidando isso de uma maneira também muito natural porque o campo de atuação da cultura é tão grande que você nunca vai conseguir dar conta de totalidade dessa demanda." (PP NilópoliS 2)

"Existem justamente por causa do regimento, da lei, que o conselheiro, a plenária segue, quer seguir e algumas pessoas acham que não...Aí embola e há o conflito pessoal do conselho. Já não é mais conselheiro, é pessoal. (...).Aí se você não souber administrar vira conflito pessoal. E aí quando vira pessoal dá uma esfriada feia no conselho.” (PP Nilópolis 1)

Logo, os conselheiros muitas vezes não conseguem separar questões de cunho pessoal das suas demais atividades, aprofundando as divergências dentro dos conselhos.

"Conflitos de opinião, todo, todo lugar tem, não é, e acho ate importante que tenha, que as pessoas não podem pensar a mesma coisa, as pessoas pensam diferente, então tem conflito de opinião, mas no geral todos querem a mesma coisa, né, o, o bem da cultura da cidade. Conversa, é... democraticamente e participativamente, cada um vai colocar aquilo que quer, vai se pensar sobre aquilo, refletir sobre aquilo e se não houver consenso vai votar, votação.” (PP SJM)

Assim como para Fleury (2009) os conflitos de idéia e interesses sociais fazem com que a política aconteça, os conselheiros também relatam que os conflitos são positivos na dinâmica de participação dos conselhos municipais de cultura.

"Mas é diferente... a gente sabe é muito diferente a linguagem da sociedade civil e do poder público. Eu acho que é por isso que tem muita... briga, tem muitas vezes muita discussão, né!..” (SC Japeri)

"O único problema que tivemos foi essa... essa reprovação do regimento, que poxa, é você dizer que.. Você não apoiar o (próprio) regimento do Conselho de
Cultura é você dizer que você não quer o Conselho, né?" (SC Magé)

"Foi o que falei da saia justa, já teve um probleminha com o presidente do conselho, (...) sobre essas questões que existe um regimento e uma lei Eles têm que seguir esse regimento e a gente tem que seguir essa lei...Muitas das vezes ele não entendia isso, e era uma briga."(PP Nilópolis 2)

\begin{abstract}
“deixando bem claro...não é questão de política ou coisa parecida, é questão de continuidade do trabalho. Enquanto a gente tinha muita autonomia com o secretario anterior com o atual agente tem muito a questão de personali...é personalista do atual secretario que vem batendo assim muito de frente com o conselho e o conselho atualmente ta muito esvaziado aqui na cidade e de algum bom tempo que não faz reuniões." (SC Nilópolis 1)
\end{abstract}

O principal conflito existente no conselho é embate entre os conselheiros da sociedade civil e os do poder público.

\begin{abstract}
"Esse primeiro mandato do conselho municipal de cultura, ele teve algumas complexidades (...) havia uma espécie de disputa, até político-partidária, dentro, dentro do primeiro mandato do conselho. “(PP Queimados 1)
\end{abstract}

Os conflitos entre os conselheiros da sociedade civil e poder público acontecem muitas vezes em razão das disputas político-partidário. Os conselhos acabam sendo também lugares utilizados por alguns conselheiros como plataforma política para ganhar notoriedade e concorrer para cargos políticos.

Para entender a dinâmica de participação social dos conselhos municipais de cultura, cabe compreender as relações de poder e como elas influenciam nas ações do conselho.

"Então, foi levado para o grupo, e a maioria deles, foi exatamente isso, olha, a minha instituição me indicou, eu achei interessante, mas eu não sei nada sobre o conselho né, eu queria saber, o que é o conselho, como é que funciona, porque eu estou aqui." (PP Japeri) 
"Pessoas ou organizações? Não, eu não vejo isso, mas se tiver, se alguém se deixar se influenciar, é porque que não tem essa pressão, esse tipo de coisa, é porque a pessoa é influenciável, porque não tem essa pressão, o conselho é paritário, é uma parte civil, uma parte publica, não é, não tem grandes instituições interessadas, (...), isso normalmente acontece quando você tem, né, grande capital interessado, a gente não tem isso, não tem isso.” (PP SJM)

"Enquanto membros do conselho, acho que todos, todas as organizações, todas as pessoas que fazem parte influenciam, (...) é onde a gente briga pra que realmente a instituição venha e indique uma pessoa que pode representar a instituição é nesse sentido de fortalecer entendeu? Porque pro governo é muito fácil tomar as decisões entendeu? Então, é legal que essa decisão não seja tomada com a sociedade civil e governo, que seja um benefício para a população. $O$ governo ele vai tomar a decisão para a população, mas se a população não tem esse conhecimento, de repente ela nem faz sentido, entendeu? Eu acho que quando você recebe a política pública tomando a consciência dessa política pública, porque que ela ta vindo, é muito fácil, é muito mais fácil ela acontecer e ficar.." (PP Japeri)

Conforme dito anteriormente, a participação social nos conselhos acontece por meio de organizações da sociedade civil. Dessa forma, as organizações influenciam diretamente $\mathrm{o}$ funcionamento do conselho. Porém, algumas organizações aproveitamse do potencial que tem no município em benefício próprio.

"A contaminação acaba vindo de todos os lados né...De dentro pra fora e de fora pra dentro."(SC Caxias)

"E ai, a gente teve entre alguns membros da primeira gestão do conselho, é...é, claramente a gente começou a perceber que havia um interesse pessoal, particular e político-partidário, de promoção, de divulgação de seu nome, para ventilar futuras e possíveis candidaturas partidárias, no campo de, de.., vereador né. E.. E isso, foi complicando a coisa, alguns, outros membros do conselho perceberam isso, e, esvaziaram o conselho, havia uma liderança no conselho nessa, nesse segmento, nessa político-partidária, que acabou enfraquecendo totalmente as possíveis conquistas do conselho." (PP Queimados 1)

Os trechos acima relatam sobre como a influência de alguns grupos políticos dentro do conselho acabaram afetando a participação social. No caso do município de Queimados, por exemplo, o conselho foi dissolvido.

"Tem que responder? Risos. Olha hoje eu
acho que o Conselho beneficia só um lado.
Que não é o nosso. Eu acho que nós ainda
estamos é... nós ainda estamos sendo...
como posso falar pra você... não é ingênuo
não. Mas por um outro lado ainda tem
sim pessoas que estão ali e estão sendo
ingênuas." (SC SJM)

"Porque se o recurso público pra trabalhar com culturas populares tá disputando com o recurso público que vai fazer a festa do peão de boiadeiro, tá aí claro uma disputa de poder. Que tá longe de ser ideológica...é uma disputa de interesses financeiros mesmo. (...) não é ideológica não, é disputa de poder...” (SC Mesquita)

Nos conselhos, de acordo com os dados, há uma constante disputa de poder entre os grupos para ver quem vai ser mais beneficiado com as decisões tomadas.

"Ela faz uma reunião paralela no dia e hora do Conselho. Mesmo ela sendo conselheira, ela faz isso.(.) Essas pessoas, elas estão organizadas entre si. Um grupo (...) Trabalham dessa maneira." (SC NI)

\begin{abstract}
"Então, existia ali, uma questão políticopartidário, e aí pessoas, que estavam ligadas a essas pessoas dentro do conselho, as próprias pessoas que estavam dentro do conselho já tinham um objetivo, na minha opinião, menor, um objetivo menor, de levantar um nome, (...), eu acho que o conselho não é o lugar disso. Existem vários lugares para isso, mas no conselho não, eu acho que o conselho é um lugar de participação e construção, e não de levantar nome político-partidário pra vereador"(PP Queimados 1)
\end{abstract}

Os trechos reforçam o que indica Bordenave (1983), uma vez que a organização em grupos é importante 
no processo de participação, pois ajuda a alcançar as necessidades econômicas e sociais desse grupo.

Por fim, o sexto aspecto a ser analisado sobre o processo de participação nos conselhos diz respeito à relação entre cultura e desenvolvimento. Durante as entrevistas foram surgindo questões relevantes sobre a importância da cultura. O SNC e o PNC inclusive ressaltam que além da vertente mercadológica, a cultura também deve ser considerada pela sua importância cidadã e simbólica, por isso, torna-se importante entender como a cultura afeta a participação social.

\begin{abstract}
"pode dizer que a cultura de uma pessoa é aquilo que ele aprende no decorrer da sua vida. Então muitas das vezes você pega pessoas analfabetas, mas que tem uma cultura muito grande. Porque viu muita coisa, porque conversa muito com as pessoas, ele não sabe lê e nem escrever, mas ele se comunica com as pessoas é... ele tem varias historias pra contar, tem umas vida inteira de coisas que ele pode passar pra você que são ensinamentos, e se é um ensinamento, se é alguma coisa que se aproveite é cultura, né!” (SC Nilópolis)
\end{abstract}

Os aspectos simbólicos da cultura são importantes para a formação cidadã da população. Através de contato com a cultura, as pessoas são confrontadas sobre a própria realidade e o papel que exercem na sociedade. Sendo assim, isso reafirma o que Carvalho (2009) fala sobre a visão simbólica, que faz com que o Estado pense no papel da cultura para além dos fins mercadológicos. Porém, as práticas propostas devem ir além do discurso e, a autonomia e a participação deve ser conquistada.

"Ninguém vai deixar de olhar para a Saúde para dar dinheiro para a Cultura. Infelizmente! Mas, a gente sabe que a Cultura faz parte da essência do povo, do modo de vida do povo. E isso tem que ser valorizado. É essa nossa grande busca, né? Da valorização da Cultura enquanto ser humano, enquanto pessoa, enquanto... (pausa) é... (pausa)constru... (pausa) constru(pausa), a construção do nosso sujeito, né? A cultura faz parte disso." (PP Japeri 2)

\footnotetext{
“O desenvolvimento humano hoje ele precisa ta refletindo diretamente nas questões culturais a, a outros aspectos nessa área mais humana, porque aí é ligado diretamente a qualidade de vida, o quanto a vida das pessoas podem estar
}

mais interessante e melhores baseadas na, na maneira como ela vive e em relação a liberdade e direitos, né, civis." (PP Nilópolis 2)

Assim como a cultura é considerada fundamental para o desenvolvimento humano, segundo Bordenave (1983) a participação social também é inerente ao comportamento humano.

\begin{abstract}
"Então, eu acho assim, quando se tem um conselho atuante, você pode buscar mais e até trabalhar com essa questão da consciência mesmo da população, cultura também é importante né, o ser humano não é só a questão da alimentação e educação. " (PP Japeri)
\end{abstract}

\begin{abstract}
““'Não no governo, mas na sociedade civil e eu nem sabia o que era sociedade civil... Eu sempre tive a consciência de que a cultura ela muda muito o comportamento, o hábito, pensamento, opinião, de muita gente...Né, a cultura foi o $4^{\circ}$ pilar, foi considerado já, o $4^{\circ}$ pilar da formação de cidadania. A gente tem aí educação, saúde, sustentabilidade e cultura. Então no momento que você não consegue acionar essa responsabilidade cultural, a cultura vai ficar como ela sempre é, né.." (PP Nilópolis 1)
\end{abstract}

\begin{abstract}
"A..se pode dizer que a cultura de uma pessoa é aquilo que ele aprende no decorrer da sua vida. Então muitas das vezes você pega pessoas analfabetas, mas que tem uma cultura muito grande.." (SC Nilopólis1)
\end{abstract}

Assim como Freire (1979) associava a educação à conscientização do povo, também se pode dizer que a partir dos relatos dos entrevistados, que a cultura provoca a conscientização crítica à população sobre a sua realidade. Um aspecto importante da cultura que muitas vezes não está presente nos conselhos municipais de cultura é a diversidade cultural, já que há grupos de determinados segmentos que são privilegiados em detrimento de outros. Pois, de acordo com Maranhão e Teixeira (2005), para que os espaços participativos sejam efetivos, é necessário que atenda a pluralidade da sociedade.

Em síntese, a partir da análise de dados, estabelecemse, no Quadro 3, os aspectos centrais que influenciam 
a dinâmica de participação social nos conselhos municipais de cultura da Baixada Fluminense:

Quadro 3. Aspectos que influenciam a dinâmica de participação nos conselhos

\section{Formas de Participação \\ Participação prevista em lei \\ Pouco estímulo à \\ participação nos conselhos \\ A participação da sociedade civil acontece \\ por meio das organizações \\ Processo de participação \\ acontece a partir de \\ estrutura e processos \\ burocráticos \\ A comunicação no processo de participação tem traços de informalidade}

\section{Conflitos e Relações de Poder}

Influência de organizações no funcionamento do conselho

Conflitos entre Sociedade civil e poder público

Resolução de conflitos através do voto durante reuniões

Questões pessoais provocam conflitos

Existência de disputa de poder

Existência de disputas político-partidárias

\section{Cultura e}

\section{Desenvolvimento}

Importância dos aspectos simbólicos da cultura

Importância da relação entre cultura e desenvolvimento humano

\section{Tomada de Decisão}

As decisões acontecem por voto

Decisão final centralizada

no presidente

O conselho é informado

de decisões tomadas

previamente pelo Poder

Público

Há influência de grupos na decisão

Existência de decisões de baixa importância para o desenvolvimento do setor cultural

\section{Controle}

Controle burocrático que acontece através das atas e de reuniões

Não há um processo de controle bem definido

Não há controle a respeitos das políticas públicas de cultura do município

Dificuldades de estabelecimento de objetivos e resultados esperados

Controle do poder público via representação dos conselheiros

\section{Papel da Sociedade Civil}

Pouca articulação entre entes da sociedade civil Fraca mobilização e empoderamento da sociedade civil
Cultura como elemento importante para conscientização do povo

Importância de reconhecer a diversidade cultural

A cultura como dimensão não prioritária na atuação dos Municípios

Fonte: Elaborado pelas autoras.

Por fim, após determinar os principais fatores que influenciam a participação social nos conselhos de políticas culturais caberia estabelecer algumas considerações. Primeiramente, tomando por base a ideia de Demo (2009) de que participação é conquista, é importante destacar que a expansão da participação social por meio dos conselhos de políticas culturais representa sim um resultado de anos de luta dos ativistas culturais, porém também é altamente dependente da estrutura do Estado para sua manutenção. Dessa forma, os conselhos são espaços conflituosos em que tanto ações de controle quanto de resistência são verificadas.

A respeito dos efeitos das instâncias participativas e do próprio papel da sociedade civil nesses espaços, a ideia de Tenório (2008) de que a participação tem como objetivo impedir que as decisões fiquem concentradas nas mãos de poucos, mas sim garantir que os direitos sejam cumpridos para todos, permite uma importante reflexão. $\mathrm{Na}$ área da cultura, especialmente em regiões de escassez de recursos e atenção do Estado, os conselhos representam uma real possibilidade de pequenas transformações locais que evidenciam a relação entre cultura e desenvolvimento.

Claro que uma série de desafios são enfrentados para que os conselhos consigam contribuir para a efetividade dos processos de participação social. Um dos desafios que Maranhão e Teixeira (2006) apontam para a participação social é a dificuldade de articulação entre os espaços participativos. Nos conselhos municipais de políticas culturais essa questão é mais complexa, pois a consistência da atuação de tais órgãos depende também de órgãos federais e estaduais.

$\mathrm{Na}$ figura 2 a seguir, apresenta-se um esquema do processo de participação social nos conselhos municipais de políticas culturais. 
Figura 2 . Dinâmica do Processo de

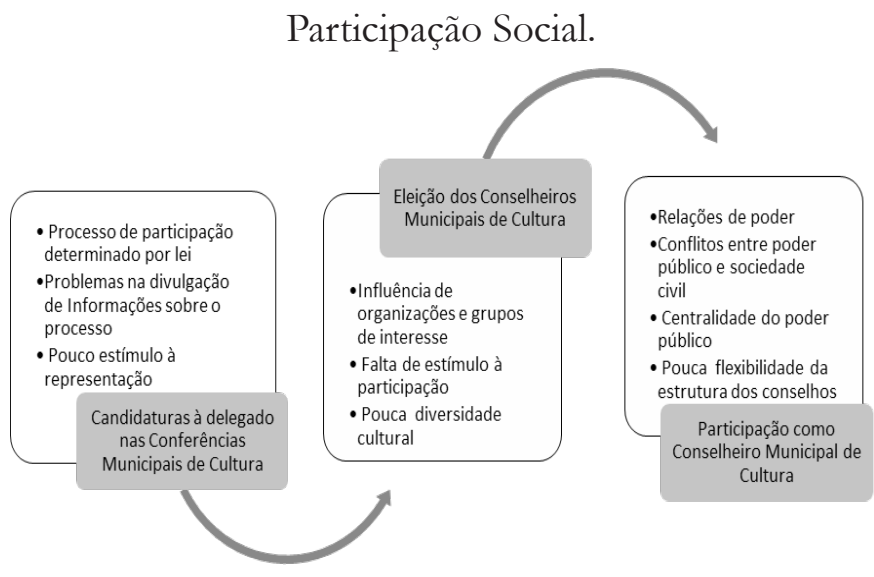

Fonte: elaborado pelas autoras.

Conforme a figura apresentada, a participação social nos conselhos municipais de políticas culturais na Baixada Fluminense, tem várias etapas, começando pela participação nas conferências de municipais de cultura, com a posterior candidatura a conselheiro de cultura, respectiva eleição como conselheiro e, finalmente, termina com a atuação como conselheiro. Cabe ressaltar que, alguns elementos influenciam fortemente esse processo destacando-se, dentre diversos aspectos, as questões estruturais, as disputas de poder e os conflitos entre poder público e sociedade civil.

Por fim, tendo em vista esses aspectos, cabe destacar que a tipologia dos níveis de participação apresentadas por Bordenave (1983) embora contribua para a compreensão do processo de participação social, parece não ser suficiente para explicar os processos de participação em conselhos municipais de políticas culturais, diante das especificidades do setor cultural, das características variadas da região em que tais conselhos estão instalados e do momento do processo participativo que está sendo analisado.

\section{Considerações Finais}

Portanto, conclui-se que o processo de participação social nos conselhos municipais de cultura da Baixada Fluminense acontece de forma limitada devido à natureza da política pública e das organizações que determinam a estrutura destes. Além disso, outros fatores influenciam a participação e consequentemente a efetividade dos conselhos, como as características da gestão e também as relações de poder entre os atores envolvidos.

Também foi possível perceber que a efetividade dos conselhos municipais de cultura requer a ampliação da participação social nesses espaços. Os conselhos representam papel central na democratização das decisões de políticas culturais. Porém vários fatores representam entraves para a efetividade destes no espaço público. Um dos principais objetivos dos conselhos municipais de políticas culturais é a descentralização das decisões de políticas públicas, porém, os conflitos entre os interesses do poder público e da sociedade civil dificultam que isto aconteça.

Os conselhos, como identificado na pesquisa de campo, são espaços de disputa de diversos grupos dentre eles: grupos políticos partidários, grupos religiosos, grupos associados ao poder público, grupos de ativistas culturais, entre outros. Dessa forma, os conflitos e as disputas por recursos de poder estão sempre presentes e influenciam a dinâmica de participação social. Porém, o poder público na maioria das vezes tende a ter êxito nessas disputas e centralizar as decisões para atender ao governo.

Embora os conselhos municipais de cultura da Baixada Fluminense tenham grandes desafios para sua efetividade, especialmente no que tange as decisões de políticas culturais, eles são um importante espaço de diálogo entre a sociedade civil e o poder público. A participação social na área da cultura pressupõe avanços na dinâmica das instâncias participativas e nas políticas culturais. Além disso, é fortemente impactada pela mobilização da sociedade civil na apropriação dos espaços públicos de participação. Por fim, a partir do ponto de vista teórico, é necessário ampliar o debate sobre as formas organizacionais e as estruturas das instituições participativas que as mesmas possam contribuir de fato para a democratização e para a efetividade da participação social.

\section{Referências}

ABERS, R.; SERAFIM, L.; TATAGIBA, L.

Repertórios de interação estado-sociedade em um estado heterogêneo: a experiência na Era Lula. Dados, Rio de Janeiro, v. 57, n. 2, p. 325-357, Jun, 2014 .

AMMAN, S. B. Participação Social. São Paulo: Cortez \& Moraes, 1978. 
BARBALHO, A. O orçamento participativo e os dados da Munic Cultura 2006: o caso de Fortaleza. In: CALABRE, L (Org). Políticas Culturais: reflexões sobre gestão, processos participativos e desenvolvimento. São Paulo: Itaú Cultural; Rio de Janeiro: Fundação Casa de Rui Barbosa, 2009.

BORDENAVE, J.E.D. O que é participação? São Paulo: Editora Brasiliense, 1983.

CANEDO, D. A participação social na elaboração de políticas públicas de cultura na Bahia. In: CALABRE, L (Org). Políticas Culturais: reflexões sobre gestão, processos participativos e desenvolvimento. São Paulo: Itaú Cultural; Rio de Janeiro: Fundação Casa de Rui Barbosa, 2009.

CARVALHO, C. A. O estado e a participação conquistada no campo das políticas públicas para a cultura no Brasil. In: CALABRE, L (Org). Políticas Culturais: reflexões sobre gestão, processos participativos e desenvolvimento. São Paulo: Itaú Cultural; Rio de Janeiro: Fundação Casa de Rui Barbosa, 2009.

CASTRO, L. R. de; MATTTOS, A. R. O que é que a política tem a ver com a transformação de si? Considerações sobre a ação política a partir da juventude. Análise Social, vol. XLIV (193), 2009.

COSTA, F. L.; CUNHA, A. P. G. Sete Teses Equívocas sobre a Participação Cidadã: o dilema da democracia direta no Brasil. O\&S v.17, n.54, p. 543553, Jul/Set, 2010.

DEMO, P. Participação é conquista: noções de política participativa. $6^{a}$ EDIÇÃO, São Paulo: Cortez, 2009.

FARIA, H. Conselhos Municipais de Cultura: cultura participativa e cidadania cultural. In: CALABRE, L (Org). Políticas Culturais: reflexões sobre gestão, processos participativos e desenvolvimento. São Paulo: Itaú Cultural; Rio de Janeiro: Fundação Casa de Rui Barbosa, 2009

FLEIG, D., OLIVEIRA, L.C.F.; BRITO, M. J. Democracia, Participação e Gestão Social: Desafios da Construção dos Programas de Ação Temática de uma Organização Não-Governamental.

Organização \& Sociedade, v. 13, n.38, 2006.

FLEURY, S. Democracia e Socialismo: o lugar do sujeito. In: FLEURY, S ; LOBATO, L. V. C.(Org.).Participação, Democracia e Saúde. Rio de Janeiro: CEBES, 2009, p.24-47.

FREIRE, P. Conscientização: teoria e prática da libertação: uma introdução ao pensamento de Paulo Freire. São Paulo: Cortez \& Moraes, 1979.

IBGE. Perfil do Municípios Brasileiros: 2009. Rio de Janeiro, 2010.

MARANHÃO, T. A.; TEIXEIRA, A. C. C.

Participação no Brasil: dilemas e desafios contemporâneos. In: ALBURQUERQUE, M. C. (org). Participação Popular em Políticas Públicas: espaço de construção da democracia brasileira. São Paulo: Instituo Polis, 2006.

MINAYO, M. C. S. Análise qualitativa: teoria, passos e fidedignidade. Ciênc. Saúde Coletiva, Rio de Janeiro, v. 17, n. 3, p. 621-626, 2012.

MINC- Ministério da Cultura. Guia de orientações para os municípios - Sistema Nacional de Cultura: perguntas e respostas. Brasília: MINC/ CNPC/SAI, 2011.

PAULA, A.P. P. Administração Pública Brasileira entre o Gerencialismo e a Gestão Social. Revista de Administração de Empresa, v.45, n. 1, Jan/Mar, 2005.

ROESCH, A. Projetos de estágio e de pesquisa em administração: guias para estágios, trabalhos de conclusão, dissertações e estudo de casos. SP: Atlas, 1996.

TEIXEIRA, A. C. Formação dos Conselhos no Brasil. IN: FARIA, Hamilton, MOREIRA, A.; VERSOLATO, F., (Orgs.). Você quer um bom conselho? Conselhos municipais de cultura e cidadania cultural. São Paulo: Instituto Pólis, 2005.

TENÓRIO, F. G. O mito da participação. Revista de Administração Pública, v. 24, n. 3, 1990.

TENÓRIO, F. G.; VILLELA, L. E.; DIAS, A. F; GURJÃO, F. V.; PORTO, E. C.; VIANA, B. Critérios para a avaliação de processos decisórios participativos deliberativos na implementação de políticas públicas. Anais do evento ENAPG. Bahia: 2008. 